\title{
Effects of Gocovri (Amantadine) Extended-Release Capsules on Motor Aspects of Experiences of Daily Living in People with Parkinson's Disease and Dyskinesia
}

Robert A. Hauser · Shyamal H. Mehta · Daniel Kremens •

Dustin Chernick · Andrea E. Formella

Received: January 13, 2021 / Accepted: May 5, 2021 / Published online: May 22, 2021

(C) The Author(s) 2021

\section{ABSTRACT}

Introduction: Gocovri, a bedtime-administered delayed-release/extended-release capsule formulation of amantadine, is the only drug approved by the US Food and Drug Administration as levodopa-adjunctive therapy for the treatment of OFF episodes and/or dyskinesia in Parkinson's disease (PD). Part II of the Movement Disorder Society Unified Parkinson's Disease Rating Scale (MDS-UPDRS) assesses patientperceived disability on experiences of daily living affected by PD motor symptoms. We analyzed Gocovri-related changes in MDS-UPDRS Part II ratings in two placebo-controlled clinical trials.

Methods: Baseline to week 12 changes in MDSUPDRS Part II total and item scores were

R. A. Hauser $(\varangle)$

USF Parkinson's Disease and Movement Disorders Center, Parkinson Foundation Center of Excellence, University of South Florida, 4001 E. Fletcher Ave, 6th Floor, Tampa, FL 33613, USA

e-mail: rhauser@usf.edu

\section{S. H. Mehta}

Department of Neurology, Mayo Clinic-Scottsdale, Scottsdale, AZ, USA

D. Kremens

Department of Neurology, Thomas Jefferson

University, Philadelphia, PA, USA

D. Chernick · A. E. Formella

Adamas Pharmaceuticals, Inc., Emeryville, CA, USA compared for Gocovri and placebo using pooled data from phase 3 trials (EASE LID and EASE LID $3)$.

Results: Baseline mean MDS-UPDRS Part II total score was 15.1 for Gocovri $(n=100)$ and 15.3 for placebo $(n=96)$ groups. At week 12 , the least squares mean change from baseline was -3.4 for the Gocovri group and -1.4 for placebo (treatment difference, $-2.0 ; 95 \% \mathrm{CI}-3.3$ to $-0.7 ; P=0.004)$. For Gocovri, change from baseline exceeded a published minimal clinically important difference threshold of 3.05. Gocovri-related treatment differences over placebo were driven primarily by improvement in the scale items of freezing $(-0.4 ; P<0.0001)$, tremor $(-0.4 ; P=0.002)$, getting out of bed/car/ deep chair $(-0.3 ; P=0.002)$, and eating tasks $(-0.2 ; P=0.016)$.

Conclusion: In addition to improvement in dyskinesia, Gocovri-treated participants experienced improvement in motor aspects of experiences of daily living. Analyses suggest that Gocovri may specifically improve freezing, tremor, getting out of bed/car/deep chair, and eating tasks.

Trial Registration: ClinicalTrials.gov identifiers: NCT02136914, NCT02274766.

Keywords: Amantadine extended release; Experiences of daily living; Gocovri; MDSUPDRS; Motor complications; Parkinson's disease; Treatment 


\section{Key Summary Points}

Gocovri (amantadine) extended release capsules are approved for the treatment of dyskinesia and/or OFF episodes in levodopa-treated patients with Parkinson's disease.

We sought to evaluate the effects of Gocovri on patient-perceived disability regarding motor aspects of experiences of daily living as assessed by Part II of the Movement Disorder Society Unified Parkinson's Disease Rating Scale (MDSUPDRS).

We analyzed changes in MDS-UPDRS Part II total and item scores from baseline to week 12, comparing Gocovri and placebo, using pooled data from phase 3 trials (EASE LID and EASE LID 3).

At week 12, the treatment difference for MDS-UPDRS II total score for Gocovri compared with placebo was -2.0 $(P=0.004)$, and Gocovri's change from baseline exceeded a published minimal clinically important difference threshold of 3.05 .

Gocovri-treated participants experienced significant improvements in motor aspects of experiences of daily living. Analyses indicated that Gocovri may specifically improve freezing, tremor, getting out of bed/car/deep chair, and eating tasks.

\section{DIGITAL FEATURES}

This article is published with digital features, including a summary slide, to facilitate understanding of the article. To view digital features for this article go to https://doi.org/10.6084/ m9.figshare.14534880.

\section{INTRODUCTION}

Gocovri (Adamas Pharmaceuticals, Inc., Emeryville, CA), a bedtime-administered delayed-release/extended-release capsule formulation of amantadine, is the first medication approved by the United States Food and Drug Administration for the treatment of dyskinesia and/or OFF episodes in people with Parkinson's disease (PwP) receiving levodopa-based therapy. Unlike other marketed amantadine products, Gocovri is specifically designed to be taken at bedtime. The modified-release properties of the dosage form result in an initial delay, followed by a slow rise overnight to produce high morning plasma concentrations that taper towards evening [1]. In pivotal, phase 3 dyskinesia trials, Gocovri also significantly reduced OFF time, as assessed by home diaries [2, 3], and is the only Parkinson's disease (PD) medication to date proven to significantly reduce both OFF time and dyskinesia. Since the main goal of these trials was to assess the effect of Gocovri on dyskinesia, the primary outcome measure was the Unified Dyskinesia Rating Scale (UDysRS) [4]. Other measures used in the phase 3 trials included the Movement Disorder Society Unified Parkinson's Disease Rating Scale (MDSUPDRS), the gold standard for assessing PD symptoms. One way to assess the meaningfulness of Gocovri effects is to evaluate patientrated disability using the MDS-UPDRS Part II, which is a reliable, disease-specific, patientrated disability measure that assesses motor aspects of experiences of daily living (M-EDLs) $[5,6]$. MDS-UPDRS Part II assesses the impact of parkinsonian motor features such as freezing, tremor, and salivation that may be unrelated to dyskinesia, but also includes activities such as eating, dressing, and writing that could be affected by either parkinsonian motor status or dyskinesia. Thus, MDS-UPDRS Part II provides an overall assessment of the clinical relevance of PD medications in everyday life. We therefore analyzed the MDS-UPDRS Part II results from two similarly designed phase 3 clinical trials to evaluate Gocovri effects on M-EDLs. 


\section{METHODS}

\section{Ethics Statement}

Studies EASE LID and EASE LID 3 (registered on ClinicalTrials.gov; NCT02136914, NCT02274766) were both conducted in accordance with the Good Clinical Practice Guidelines of the International Conference on Harmonisation and with the ethical principles of the Declaration of Helsinki. The studies were reviewed and approved by an independent ethics committee or institutional review board at each study center, and all patients provided written informed consent before participation. Copernicus was the institutional review board for each study. Additionally, each investigator was required to obtain institutional review board/research ethics board/independent ethics committee approval at their investigative site. Documentation of approval was obtained from each site's institutional review board/research ethics board/independent ethics committee before any subject was enrolled at that site. All subjects provided written informed consent to participate in the trials.

\section{Trial Designs and Participants}

Pooled data were used from two phase 3 randomized, double-blind, placebo-controlled clinical trials comparing Gocovri and placebo in dyskinetic PwP (EASE LID, ClinicalTrials.gov identifier NCT02136914, and EASE LID 3, NCT02274766) [2, 3]. The methodology has been published previously and was identical for both trials with the exception of trial duration. Participants were required to have $\geq 1 \mathrm{~h}$ of troublesome dyskinesia (two 30-min intervals) between 9:00 AM and 4:00 PM each day, as documented in 24-h home diaries, of sufficient severity to have at least mild impact on function (score $\geq 2$ on MDS-UPDRS item 4.2) [7]. Participants were also required to have a stable PD pharmacotherapy regimen for $\geq 30$ days before and during the study period, including use of levodopa administered $\geq 3$ times daily. Exclusion criteria included PwP with exclusively nonpeak-dose dyskinesia, deep brain stimulation, use of amantadine within the previous 30 days, estimated glomerular filtration rate $<50 \mathrm{~mL} /$ $\min / 1.73 \mathrm{~m}^{2}$, major psychiatric disorders or symptoms that would affect completion of trial assessments, clinically significant hallucinations within the past year, or presence of orthostatic hypotension. Participants were randomly assigned in a 1:1 ratio to take identically appearing capsules of placebo or Gocovri daily at bedtime. Gocovri was administered as $274 \mathrm{mg}$ amantadine base (two capsules), corresponding to $340 \mathrm{mg}$ amantadine $\mathrm{HCl}$, with half that dose (one capsule each of Gocovri and placebo) administered during the first trial week and during a taper week following final trial assessments. All participants, trial-site personnel, raters, sponsor, and contract research organization staff were blinded to treatment assignment.

\section{Efficacy Measures}

The primary outcome measure in each trial was change from baseline to week 12 in the UDysRS total score $[2,3]$. The MDS-UPDRS and PD motor state home diaries [8] were secondary outcomes in both trials. Motor assessments were conducted during the participant's ON time, at least 30 minutes after a regularly scheduled levodopa dose, while the participant was experiencing typical dyskinesias. Clinic visits occurred at baseline and treatment weeks $2,8,12,18$, and 24 in EASE LID, and at baseline and at treatment weeks $2,4,8$, and 12 in EASE LID 3. PD motor diaries were completed for the 48 hours prior to each clinic visit. For the pooled analysis, results were used from weeks 2 , 8 , and 12 , which were the assessment points common to both trials.

Part II of the MDS-UPDRS assesses $13 \mathrm{M}$-EDL items: speech; saliva and drooling; chewing and swallowing; eating tasks; dressing; hygiene; handwriting; doing hobbies and other activities; turning in bed; tremor; getting out of bed, a car, or a deep chair; walking and balance; and freezing. Participants score each item as 0 (normal), 1 (slight), 2 (mild), 3 (moderate), or 4 (severe), on an anchored scale with reference to their ability to perform a task, or the impact of a symptom on daily activities, during the 
preceding week [9]. The progression of disability scores is anchored such that a score of 2 (mild) represents a threshold at which symptoms are sufficient to cause at least modest impact on function [7].

\section{Efficacy Analysis}

The modified intent-to-treat (mITT) population included all randomized subjects (pooled from both studies) who received study drug and had $\geq 1$ post-baseline UDysRS assessment. Mean changes from baseline in MDS-UPDRS Part II total and individual item scores were tested for statistically significant differences between Gocovri and placebo using a mixedeffects model with repeated measures (MMRM). The model included categorical effects for treatment group, stratified by trial, visit (weeks 2,8 , and 12), and the interaction between treatment group and visit. All statistical tests were performed using a two-sided, 5\% significance level. An improvement of $\geq 3.05$ points in the MDS-UPDRS Part II is reported to be clinically relevant [10]. The software used for these analyses was SAS version 9.4 (SAS Institute, Cary, NC, USA). No corrections were made for multiple comparisons.

\section{Safety Measures}

Safety analyses have been previously reported for all participants who received $\geq 1$ dose of study drug (safety population) [2, 3, 11, 12]. Investigators were responsible for recording all directly observed and participant-reported adverse events (AEs). Each $\mathrm{AE}$ was coded according to the Medical Dictionary for Regulatory Activities (MedDRA) version 17.0.

\section{RESULTS}

\section{Trial Participants}

Participant disposition has been described previously in the report of each trial and in a pooled analysis [2, 3, 11, 12]. In total, 303 individuals were screened and 198 were treated
(100 received Gocovri and 98 received placebo; safety set). The pooled mITT population comprised 196 participants (100 Gocovri, 96 placebo). Among these, 187, 173, and 169 participants provided MDS-UPDRS Part II data at 2,8 , and 12 weeks, respectively $(97,84$, and 82 for Gocovri and 90, 89, and 87 for placebo).

Baseline characteristics of the pooled mITT population are presented by treatment group in Table 1. Mean participant age was 64.7 years, $55.6 \%$ were male, and $94.4 \%$ were white. On average, participants had been taking levodopa for 7.7 years and had been experiencing dyskinesia for 3.8 years. Baseline mean (SD) MDSUPDRS Part II total scores were similar between groups: $15.1(6.6)$ for Gocovri $(n=97)$ and 15.3 (5.9) for placebo $(n=90)$. More than $60 \%$ of participants scored 1 (slight impact on function) or greater for each of the 13 MDS-UPDRS Part II items except chewing and swallowing (38.8\% of participants), and freezing $(57.1 \%$ of participants), with at least $10 \%$ scoring 3 or 4 (moderate or severe impairment, respectively) for items of hobbies $(10.2 \%)$, tremor $(10.2 \%)$, speech $(11.7 \%)$, saliva and drooling (14.8\%), getting out of bed/car/deep chair (15.3\%), walking and balance (19.4\%), and handwriting (21.4\%) (Fig. 1).

Least squares (LS) mean change from baseline in MDS-UPDRS Part II by treatment visit is shown in Fig. 2. At week 12, the overall LS mean change was -3.4 for Gocovri and -1.4 for placebo, with a placebo-adjusted treatment difference of -2.0 (95\% CI -3.3 to $-0.7 ; P=0.004)$. More than half $(54.9 \% ; n / N=45 / 82)$ of Gocovri-treated participants had $\mathrm{a} \geq 3$-point reduction (improvement) in MDS-Part II total score, versus $35.6 \%(n / N=31 / 87)$ of those given placebo, and more than a quarter $(28.0 \%$; $n=23$ ) of Gocovri-treated participants had a $\geq 7$-point change, versus $13.8 \% \quad(n=12)$ of those given placebo. Conversely, an increase (worsening) of $\geq 3$ points was experienced by $8.5 \%(n=7)$ of Gocovri-treated participants, versus $14.9 \%(n=13)$ of those given placebo.

The LS mean treatment differences for each M-EDL item at week 12 are shown in Fig. 3. Improvement in MDS-UPDRS Part II total score was driven primarily by reductions in item scores for freezing, tremor, getting out of 
Table 1 Baseline characteristics by treatment group (pooled mITT populations)

\begin{tabular}{|c|c|c|}
\hline Variable & Gocovri $(n=100)$ & Placebo $(n=96)$ \\
\hline Age, years & $64.2(9.5)$ & $65.3(8.8)$ \\
\hline Male sex, \% & 54.0 & 57.3 \\
\hline White race, \% & 96.0 & 92.7 \\
\hline Duration of Parkinson's disease, years & $9.8(4.7)$ & $9.7(4.1)$ \\
\hline Duration of levodopa treatment, years & $7.8(3.9)$ & $7.6(4.1)$ \\
\hline Duration of dyskinesia, years & $4.0(3.1)$ & $3.6(2.5)$ \\
\hline OFF time, h/day & $3.0(2.3)$ & $2.6(2.0)$ \\
\hline \multicolumn{3}{|l|}{ MDS-UPDRS Part II score } \\
\hline Total score & $15.1(6.6)$ & $15.3(5.9)$ \\
\hline \multicolumn{3}{|l|}{ M-EDL item } \\
\hline 2.1. Speech & $1.3(1.0)$ & $1.3(1.0)$ \\
\hline 2.2. Saliva and drooling & $1.3(1.2)$ & $1.2(1.1)$ \\
\hline 2.3. Chewing and swallowing & $0.4(0.7)$ & $0.5(0.7)$ \\
\hline 2.4. Eating tasks & $0.9(0.8)$ & $1.0(0.7)$ \\
\hline 2.5. Dressing & $1.2(0.7)$ & $1.2(0.7)$ \\
\hline 2.6. Hygiene & $0.9(0.6)$ & $0.8(0.6)$ \\
\hline 2.7. Handwriting & $1.5(1.1)$ & $1.6(1.2)$ \\
\hline 2.8. Doing hobbies and other activities & $1.5(0.9)$ & $1.4(0.8)$ \\
\hline 2.9. Turning in bed & $1.1(0.7)$ & $1.1(0.8)$ \\
\hline 2.10. Tremor & $1.3(1.0)$ & $1.2(0.9)$ \\
\hline 2.11. Getting out of a bed, a car, or a deep chair & $1.5(1.0)$ & $1.4(1.0)$ \\
\hline 2.12. Walking and balance & $1.4(1.0)$ & $1.4(1.0)$ \\
\hline 2.13. Freezing & $1.0(1.1)$ & $1.2(1.1)$ \\
\hline
\end{tabular}

Data are presented as mean (SD) unless otherwise noted $M D S$-UPDRS Movement Disorder Society Unified Parkinson's Disease Rating Scale, $M$-EDL motor aspects of experiences of daily living, $m I T T$ modified intent to treat

bed/car/deep chair, and eating tasks. Gocovrirelated treatment differences were -0.4 $(P<0.0001$ vs placebo $)$ for freezing, -0.4 $(P=0.002)$ for tremor, $-0.3(P=0.002)$ for getting out of bed/car/deep chair, and -0.2 $(P=0.016)$ for eating tasks. Although not statistically significant, treatment differences for six of the remaining nine items (speech, saliva and drooling, hygiene, handwriting, hobbies, and turning in bed) showed numerical improvement relative to placebo. No items significantly favored the placebo group, though chewing/swallowing favored placebo numerically.

The ability to show improvement on MDSUPDRS Part II is predicated upon the presence 


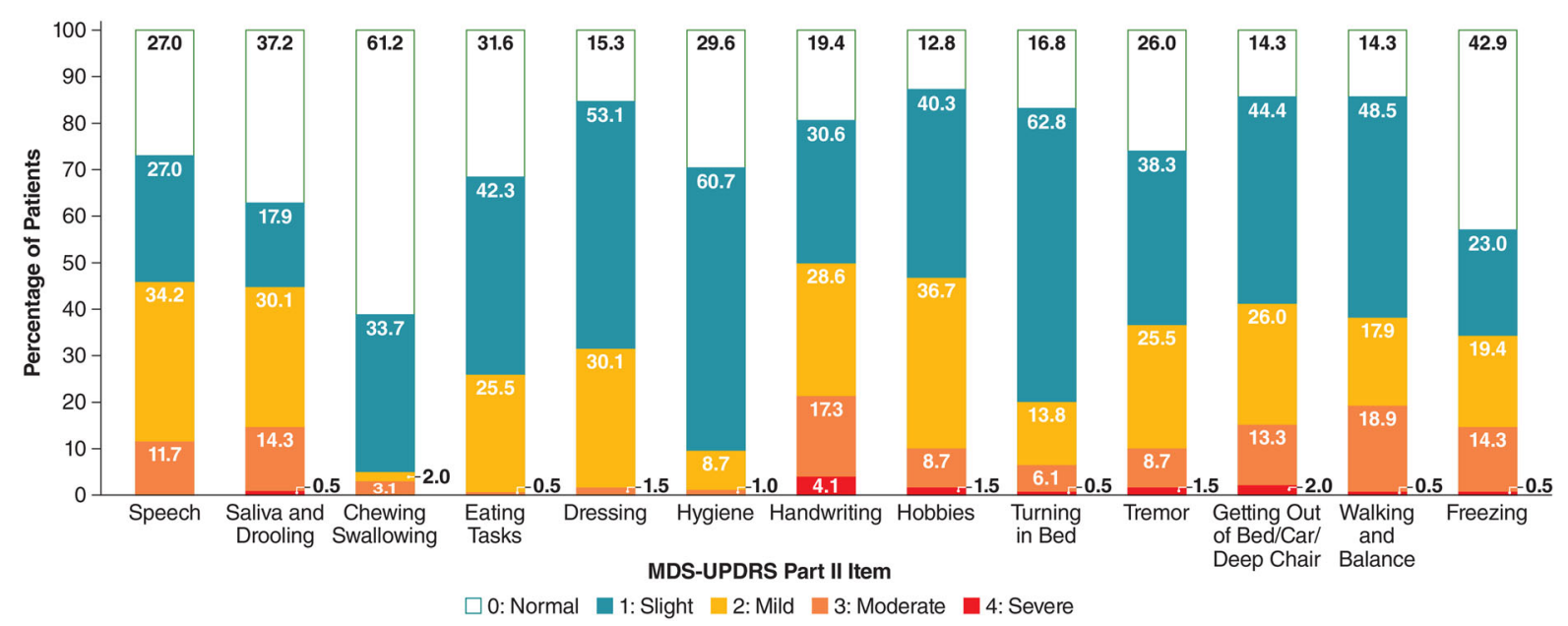

Fig. 1 Distribution of MDS-UPDRS Part II M-EDL item scores for all participants at baseline. MDS-UPDRS Movement Disorder Society Unified Parkinson's Disease Rating Scale, $M-E D L$ motor aspects of experiences of daily living

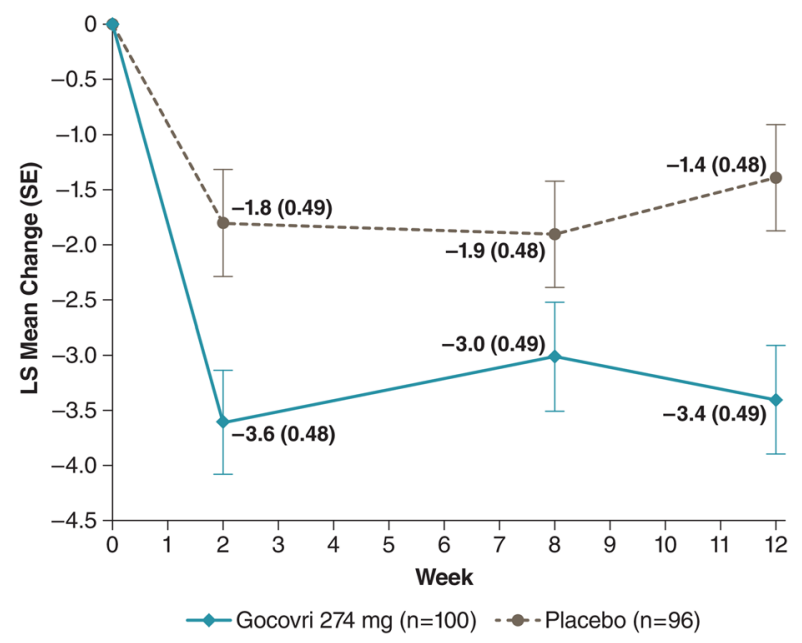

Fig. 2 Time course of LS mean change from baseline in MDS-UPDRS Part II total score among all participants (pooled mITT population). The LS mean (SE) [Gocovriplacebo] treatment differences were: week 2: $-1.8(0.68)$ $P=0.009$; week 8: $-1.1(0.68)$ ns; week 12: $-2.0(0.68)$; $P=0.004$. $P$ values are based on the comparison between Gocovri vs. placebo from the MMRM model with change from baseline as the dependent variable and the baseline value as a covariate. The model includes categorical effects for treatment group, study, and visit (weeks 2, 8, and 12), and the interaction between treatment group and visit. $L S$ least squares, MDS-UPDRS Movement Disorder Society Unified Parkinson's Disease Rating Scale, mITT modified intent to treat, $M M R M$ mixed-effects model repeated measure, $S E$ standard error and degree of impairment in each item at baseline. Movement of individuals from scores of $\geq 2$ (problematic) at baseline to scores of 0 or 1 (nonproblematic) at week 12 , and vice versa are shown in Table 2 (with "problematic" meaning scores at which there is at least a modest impact on daily function) [7]. For the four items showing significant treatment differences (freezing, tremor, getting out of bed/car/deep chair, and eating tasks), more Gocovri-treated participants moved from a problematic to a nonproblematic score, whereas more placebo-treated participants declined from a nonproblematic to a problematic score.

\section{Safety}

Adverse events from the pooled trials (up to 25 weeks in EASE LID [2] and up to 13 weeks in EASE LID 3 [3]) have been published previously $[12,13]$. The most commonly reported AEs (reported for $\geq 10 \%$ of Gocovri-treated participants) were hallucinations (visual or auditory), dizziness, dry mouth, peripheral edema, constipation, falls, and orthostatic hypotension (which occurs at $\geq 10 \%$ if one also includes events coded to the MedDRA preferred terms of postural dizziness, syncope, presyncope, and hypotension). 


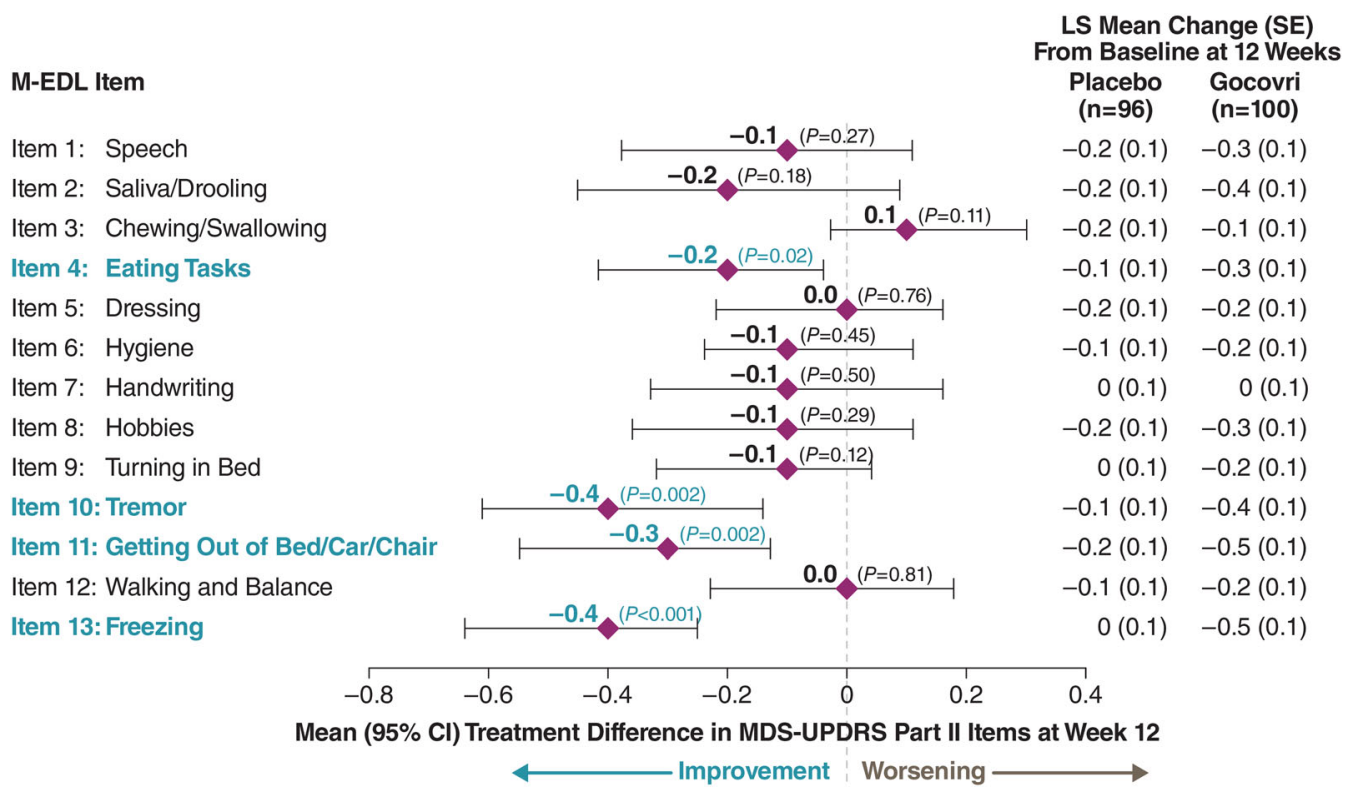

Fig. 3. 12-week changes in MDS-UPDRS Part II item scores: LS mean (95\% CI) [Gocovri-placebo] treatment differences (pooled mITT population). $P$ values are based on the comparison between Gocovri vs. placebo from the MMRM model with change from baseline as the dependent variable and the baseline value as a covariate. The model includes categorical effects for treatment group, study, and visit (weeks 2, 8, and 12), and the interaction between treatment group and visit. $L S$ least squares, $M D S$ UPDRS Movement Disorder Society Unified Parkinson's Disease Rating Scale, $M-E D L$ motor aspects of experiences of daily living, $m I T T$ modified intent to treat, $M M R M$ mixed-effects model repeated measure

\section{DISCUSSION}

Gocovri treatment significantly improved MDSUPDRS Part II total score relative to placebo over the 12-week trial periods, with LS mean changes of -3.4 points for Gocovri and -1.4 for placebo, and a placebo-adjusted treatment difference of $-2.0(P=0.004)$. MDS-UPDRS Part II has been shown to correlate well with other general and disease-specific measures of disability and quality of life [14]. Horvath and colleagues calculated mean minimal clinically important differences (MCID) for the MDS-UPDRS Part II to be -3.05 points $(95 \% \mathrm{CI}-3.91$ to -2.19$)$ for improvement and 2.51 (95\% CI 1.42-3.60) for deterioration, with an optimal threshold of \pm 2.5 points providing best discriminative accuracy in corresponding to Patient Global Impression ratings of minimal or greater change, based on receiver operating characteristic analysis [10]. Using these thresholds, the week 12, LS mean Part II score change of -3.4 points for Gocovri exceeded the MCID, whereas the mean change for placebo did not $(-1.4$ points). When considering the number of participants in each treatment group who exceeded the MCID threshold, the majority (54.9\%) of Gocovri-treated participants registered $a \geq 3$ point improvement, compared with $35.6 \%$ of participants treated with placebo. Conversely, fewer participants receiving Gocovri met the MCID for decline, with $8.5 \%$ of Gocovri-treated participants registering a $\geq 3$-point deterioration in MDS-UPDRS Part II score versus 14.9\% treated with placebo.

The effectiveness of Gocovri in reducing the participant-rated impact of dyskinesias on activities of daily living has been previously demonstrated in this same pooled population, where Gocovri significantly improved UDysRS Part 1B scores relative to placebo, with favorable ratings reaching the level of significance for 6 of 10 activities assessed on this scale, including walking and balance, eating tasks, engaging in 
Table 2 Percentages of participants shifting from problematic to nonproblematic scores at week 12 and vice versa

\begin{tabular}{|c|c|c|c|c|c|c|c|c|}
\hline \multirow[t]{2}{*}{ M-EDL item } & \multicolumn{2}{|c|}{$\begin{array}{l}\text { Participants with } \\
\text { problematic score at } \\
\text { baseline, } n\end{array}$} & \multicolumn{2}{|c|}{$\begin{array}{l}\text { Improved to } \\
\text { nonproblematic score } \\
\text { at week } 12, n / N(\%)\end{array}$} & \multicolumn{2}{|c|}{$\begin{array}{l}\text { Participants with } \\
\text { nonproblematic score } \\
\text { at baseline, } n\end{array}$} & \multicolumn{2}{|c|}{$\begin{array}{l}\text { Decline to } \\
\text { problematic score at } \\
\text { week } 12, n / N(\%)\end{array}$} \\
\hline & $\begin{array}{l}\text { Placebo } \\
(n=87)\end{array}$ & $\begin{array}{l}\text { Gocovri } \\
(n=82)\end{array}$ & $\begin{array}{l}\text { Placebo } \\
(n=87)\end{array}$ & $\begin{array}{l}\text { Gocovri } \\
(n=82)\end{array}$ & $\begin{array}{l}\text { Placebo } \\
(n=87)\end{array}$ & $\begin{array}{l}\text { Gocovri } \\
(n=82)\end{array}$ & $\begin{array}{l}\text { Placebo } \\
(n=87)\end{array}$ & $\begin{array}{l}\text { Gocovri } \\
(n=82)\end{array}$ \\
\hline Speech & 42 & 35 & $\begin{array}{l}20 / 42 \\
(47.6)\end{array}$ & $\begin{array}{l}17 / 35 \\
(48.6)\end{array}$ & 45 & 47 & $\begin{array}{l}10 / 45 \\
(22.2)\end{array}$ & $\begin{array}{l}6 / 47 \\
\quad(12.8)\end{array}$ \\
\hline Saliva and drooling & 37 & 35 & $\begin{array}{l}11 / 37 \\
(29.7)\end{array}$ & $\begin{array}{l}17 / 35 \\
(48.6)\end{array}$ & 50 & 47 & $\begin{array}{l}7 / 50 \\
\quad(14.0)\end{array}$ & $\begin{array}{l}5 / 47 \\
\quad(10.6)\end{array}$ \\
\hline $\begin{array}{c}\text { Chewing and } \\
\text { swallowing }\end{array}$ & 4 & 5 & $\begin{array}{l}4 / 4 \\
\quad(100.0)\end{array}$ & $4 / 5(80.0)$ & 83 & 77 & $3 / 83(3.6)$ & $0 / 77(0.0)$ \\
\hline Eating tasks & 23 & 24 & $\begin{array}{l}13 / 23 \\
(56.5)\end{array}$ & $\begin{array}{l}19 / 24 \\
(79.2)\end{array}$ & 64 & 58 & $\begin{array}{l}7 / 64 \\
\quad(10.9)\end{array}$ & $4 / 58(6.9)$ \\
\hline Dressing & 29 & 26 & $\begin{array}{l}15 / 29 \\
\quad(51.7)\end{array}$ & $\begin{array}{l}14 / 26 \\
(53.8)\end{array}$ & 58 & 56 & $4 / 58(6.9)$ & $\begin{array}{l}7 / 56 \\
(12.5)\end{array}$ \\
\hline Hygiene & 10 & 7 & $\begin{array}{l}6 / 10 \\
\quad(60.0)\end{array}$ & $5 / 7(71.4)$ & 77 & 75 & $2 / 77(2.6)$ & $4 / 75(5.3)$ \\
\hline Handwriting & 44 & 42 & $\begin{array}{l}9 / 44 \\
\quad(20.5)\end{array}$ & $\begin{array}{l}15 / 42 \\
(35.7)\end{array}$ & 43 & 40 & $\begin{array}{l}11 / 43 \\
(25.6)\end{array}$ & $\begin{array}{l}13 / 40 \\
(32.5)\end{array}$ \\
\hline Hobbies & 39 & 42 & $\begin{array}{l}20 / 39 \\
\quad(51.3)\end{array}$ & $\begin{array}{l}26 / 42 \\
(61.9)\end{array}$ & 48 & 40 & $\begin{array}{l}9 / 48 \\
\quad(18.8)\end{array}$ & $\begin{array}{l}6 / 40 \\
\quad(15.0)\end{array}$ \\
\hline Turning in bed & 22 & 13 & $\begin{array}{l}3 / 22 \\
\quad(13.6)\end{array}$ & $\begin{array}{l}5 / 13 \\
(38.5)\end{array}$ & 65 & 69 & $2 / 65(3.1)$ & $3 / 69(4.3)$ \\
\hline Tremor & 28 & 33 & $\begin{array}{l}7 / 28 \\
(25.0)\end{array}$ & $\begin{array}{l}24 / 33 \\
(72.7)\end{array}$ & 59 & 49 & $\begin{array}{l}12 / 59 \\
(20.3)\end{array}$ & $3 / 49(6.1)$ \\
\hline $\begin{array}{l}\text { Getting out of } \\
\text { bed/car/deep } \\
\text { chair }^{\text {a }}\end{array}$ & 38 & 34 & $\begin{array}{l}14 / 38 \\
(36.8)\end{array}$ & $\begin{array}{l}21 / 34 \\
(61.8)\end{array}$ & 49 & 47 & $\begin{array}{l}9 / 49 \\
\quad(18.4)\end{array}$ & $2 / 47(4.3)$ \\
\hline $\begin{array}{l}\text { Walking and } \\
\text { balance }\end{array}$ & 30 & 35 & $\begin{array}{l}8 / 30 \\
\quad(26.7)\end{array}$ & $\begin{array}{l}12 / 35 \\
(34.3)\end{array}$ & 57 & 47 & $5 / 57(8.8)$ & $3 / 47(6.4)$ \\
\hline Freezing & 35 & 26 & $\begin{array}{l}6 / 35 \\
\quad(17.1)\end{array}$ & $\begin{array}{l}14 / 26 \\
(53.8)\end{array}$ & 52 & 56 & $5 / 52(9.6)$ & $0 / 56(0.0)$ \\
\hline
\end{tabular}

Problematic means an item score of $\geq 2$, and nonproblematic means an item score of 0 or 1 , based on a score of 2 being the threshold at which symptoms have at least a modest impact on function [6]

$M-E D L$ motor aspects of experiences of daily living

a $n=81$

hobbies, public and social settings, exciting or emotional settings, and speech [15]. In the current analysis of MDS-UPDRS Part II, motor activities significantly improved with Gocovri 
treatment included eating, freezing, tremor, and the ability to get out of bed/car/deep chair. How much these improvements resulted from treatment effects of reducing dyskinesia relative to reducing Parkinsonism and OFF time cannot be established from the present analyses. However, the benefits observed for freezing and tremor are likely to be distinct from benefits for dyskinesia.

The substantial treatment effect $(-0.4)$ for the freezing M-EDL may represent an important outcome because effective treatment for freezing of gait is a significant unmet need in PD [16]. Of participants reporting freezing at baseline, $61.7 \%$ receiving Gocovri and $31.5 \%$ receiving placebo showed improvement on this item at endpoint, with 53.8\% (Gocovri) and $17.1 \%$ (placebo) who registered at least mild impact at baseline moving to nonproblematic scores ( 0 or 1$)$ at endpoint. Because the pathophysiology of freezing appears to be separate from the primary motor symptoms of $\mathrm{PD}$, the effect of Gocovri on this aspect of disease is particularly interesting [16-18]. Previously published data on the efficacy of amantadine on freezing are limited and inconsistent $[19,20]$. It is possible that the freezing improvement may also have contributed to the significant treatment difference $(-0.3)$ on the getting out of bed/car/deep chair item, although this is speculative. Of participants reporting tremor at baseline, $66.7 \%$ receiving Gocovri and 35.9\% receiving placebo showed improvement in this item at endpoint, with $72.7 \%$ (Gocovri) and $25.0 \%$ (placebo) who registered at least mild impact at baseline showing nonproblematic scores $(0$ or 1$)$ at endpoint. Improvement of tremor $(-0.4)$ also represents an unmet clinical need, and it is possible that this also contributed to improvement in eating tasks $(-0.2)$. In their factor analysis of MDS-UPDRS II items, Goetz et al. found that freezing of gait and getting out of bed/car/deep chair factored together as did tremor and eating tasks [7].

Gocovri was generally safe and well tolerated for up to 25 weeks in EASE LID [2] and up to 13 weeks in EASE LID 3 [3]. Hallucinations were the most commonly reported $\mathrm{AE}$ in Gocovri trials and were more common in older individuals and those with lower renal function.
Hallucination is a frequent occurrence in PwP and is influenced by multiple factors, including age and concomitant medication use [21-23]. In a 2-year open-label trial, hallucinations were managed in some individuals by dose reduction [24].

The principal limitation of our analysis is that the MDS-UPDRS Part II total score was a secondary measure in the Gocovri pivotal trials, and the pooled analysis of M-EDL items was conducted post hoc without adjustment for multiple comparisons (potential for type I error). Still, application of a conservative post hoc Bonferroni correction to the 13 items would result in three (tremor, getting out of bed/car and freezing) maintaining statistical significance. Second, for many Part II items, most participants had no or only slight impairment at baseline, providing insufficient power to detect treatment-related changes for certain M-EDLs and rendering the analysis of these items less robust. This may have resulted from trial enrollment being based on the presence of troublesome dyskinesia ( $\geq 2$ score on MDS-UPDRS Part IV item 4.2 and $\geq 1 \mathrm{~h}$ /day of troublesome dyskinesia) rather than on the presence of uncontrolled PD motor symptoms [25]. Also, because participants were required to have had dyskinesia at baseline, the applicability of our results to PwP without motor complications is uncertain. However, because improvements in these M-EDLs are more likely to be due to improved antiparkinsonian motor status, greater benefit is likely to be seen in patients with more OFF time at baseline.

We also note that Gocovri is not interchangeable with other marketed amantadine products. It was specifically developed as a once-daily, bedtime-administered formulation, containing coated pellets that provide a reliable delivery profile, with an initial delay in exposure, followed by sustained amantadine delivery over the dosing interval $[1,26]$. Because the recommended dose is higher than typically used immediate-release amantadine regimens, and the modified-release dosage form with delayed-release/extended-release profile yields a different plasma concentration versus time curve than other formulations [1, 26], with a sustained plateau from morning through early 
evening, the results of this trial may not be broadly generalizable to other amantadine products. As most patients with dyskinesia also suffer from OFF episodes, future studies/analyses should evaluate the performance of Gocovri in patients with higher levels of baseline OFF and in those without dyskinesia.

\section{CONCLUSIONS}

The results of this analysis suggest that treatment with Gocovri may improve certain M-EDLs, notably freezing and tremor (which are significant unmet needs in the PD population). This study provides one of the only sources of controlled data on amantadine's effect on tremor and freezing. These potential effects warrant further investigation.

\section{ACKNOWLEDGEMENTS}

We acknowledge and thank the trial participants and the EASE LID and EASE LID 3 trial investigators and their staff.

Funding. Sponsorship for this study and the journal's Rapid Service Fee were funded by Adamas Pharmaceuticals, Inc.

Editorial and Other Assistance. Editorial assistance in the preparation of this manuscript was provided by Robin Smith, PhD, of The Curry Rockefeller Group, LLC; support for this assistance was funded by Adamas Pharmaceuticals. Judy Lytle, PhD, of Adamas Pharmaceuticals, Inc., provided publication management; Lily Llorens, PhD, provided statistical consultation and review; Rob Howard of Veridical Solutions provided data analysis; Reed Johnson provided study management and was a consultant on the statistical plan.

Authorship. All named authors meet the International Committee of Medical Journal Editors (ICMJE) criteria for authorship for this article, take responsibility for the integrity of the work as a whole, and have given their approval for this version to be published.
Authors' Contributions. 1) Research project: A. Conception, All authors. B. Organization, All authors. C. Execution; All authors. 2) Statistical Analysis: A. Design, Coordinated by Dustin Chernick and Andrea E. Formella with Lily Llorens, Rob Howard, and Reed Johnson (acknowledged). B. Execution, Coordinated by Dustin Chernick and Andrea Formella with Lily Llorens, Rob Howard, and Reed Johnson (acknowledged). C. Review and Critique: All authors. 3) Manuscript: A. Writing of first draft, Robert Hauser and Robin Smith (acknowledged). B. Review and critique of the manuscript. All authors. C. Approval of final draft for submission: All authors.

Disclosures. RAH: Consulting fees from Acadia Pharmaceuticals, Acorda Therapeutics, Adamas Pharmaceuticals, Affiris AG, Alliance for Aging Research, Alphasights, Amneal Pharmaceuticals Inc, ApoPharma, Aranca, Cadent Therapeutics, Cerespir Inc, CNS Ratings LLC, Defined Health, Enterin Inc, Extera Partners, Gerson Lehrman Group (GLG), Global Kinetics Corporation, Impax Laboratories, Impel Neuropharma, Inhibikase, International Stem Cell Corporation, Jazz Pharmaceutics, Kaiser, Kashiv Pharma LLC, Kyowa Kirin Pharmaceutical Development, L.E.K. Consulting, Lundbeck, Lundbeck A/S, Medscape, Michael J. Fox Foundation, Mitsubishi Tanabe Pharmaceuticals, Neuro Challenge Foundation for Parkinson's, Neurocrine Biosciences, Northwestern University, Parkinson's Foundation, Parkinson's Study Group, Pennside Partners, Perception OpCo, Seelos Therapeutics, Slingshot Insights, Sunovion Pharmaceuticals Inc, Teva Pharmaceuticals, US WorldMeds, and WebMD. Research support from AbbVie Inc, Acorda Therapeutics, AstraZeneca, Axovant Sciences, Biogen Inc., Cavion, Enterin Inc, Impax Laboratories, LLC, Intec Pharma Ltd, Jazz Pharmaceuticals, NeuroDerm Ltd, Lundbeck, Michael J. Fox Foundation for Parkinson's Research, F. Hoffman-La Roche, Dart NeuroScience LLC, Prexton Therapeutics, Revance Therapeutics Inc, Sunovion Pharmaceuticals. Grant support from Parkinson's Foundation. Stock ownership in Inhibikase Therapeutics Inc and Axial Biotherapeutics. SHM: Consultant for Adamas 
Pharmaceuticals, CNS Ratings, and Abbott. Grant support from Arizona Biomedical Research Commission (ABRC) Grant ADHS 16-162411, International Essential Tremor Foundation (IETF) Grant, Eli Lilly, Pharma2B and Neuraly. DK: Consultant and speaker bureau member for Acadia, Adamas, Impax, Lundbeck, Teva, UCB, and US WorldMeds; consultant for AbbVie, Allergan, GE Healthcare, Kyowa, Merz, Neurocrine, St. Jude Medical, and Sunovion; researcher for Enterin and Revance; and researcher and consultant for Acorda. $D C$ is a former employee of Adamas Pharmaceuticals, Inc, and owns stock in Adamas. $A F$ is an employee of and owns stock in Adamas Pharmaceuticals, Inc.

Compliance with Ethics Guidelines. The studies were performed in accordance with the Helsinki Declaration of 1964, and its later amendments. All subjects provided informed consent to participate in the studies. Copernicus was the institutional review board for each study. Additionally, each investigator was required to obtain institutional review board/ research ethics board/independent ethics committee approval at their investigative site. Documentation of approval was obtained from each site's institutional review board/research ethics board/independent ethics committee before any subject was enrolled at that site. All subjects provided written informed consent to participate in the trials.

Data Availability. Where patient data can be anonymized, Adamas Pharmaceuticals, Inc. will share all individual participant data that underlie the results reported in this article with qualified researchers who provide valid research questions. Study documents, such as the study protocol and clinical study report, are not always available. Requests to access the datasets should be directed to info@adamaspharma. com.

Open Access. This article is licensed under a Creative Commons Attribution-NonCommercial 4.0 International License, which permits any non-commercial use, sharing, adaptation, distribution and reproduction in any medium or format, as long as you give appropriate credit to the original author(s) and the source, provide a link to the Creative Commons licence, and indicate if changes were made. The images or other third party material in this article are included in the article's Creative Commons licence, unless indicated otherwise in a credit line to the material. If material is not included in the article's Creative Commons licence and your intended use is not permitted by statutory regulation or exceeds the permitted use, you will need to obtain permission directly from the copyright holder. To view a copy of this licence, visit http://creativecommons.org/licenses/by$\mathrm{nc} / 4.0 /$.

\section{REFERENCES}

1. Hauser RA, Pahwa R, Wargin WA, Souza-Prien CJ, McClure N, Johnson R, et al. Pharmacokinetics of ADS-5102 (amantadine) extended release capsules administered once daily at bedtime for the treatment of dyskinesia. Clin Pharmacokinet. 2019;58(1):77-88. https://doi.org/10.1007/s40262018-0663-4.

2. Pahwa R, Tanner CM, Hauser RA, Isaacson $\mathrm{SH}$, Nausieda PA, Truong DD, et al. ADS-5102 (amantadine) extended-release capsules for levodopa-induced dyskinesia in Parkinson disease (EASE LID study): a randomized clinical trial. JAMA Neurol. 2017;74(8):941-9. https://doi.org/10.1001/ jamaneurol.2017.0943.

3. Oertel W, Eggert K, Pahwa R, Tanner CM, Hauser $\mathrm{RA}$, Trenkwalder C, et al. Randomized, placebocontrolled trial of ADS-5102 (amantadine) extended-release capsules for levodopa-induced dyskinesia in Parkinson's disease (EASE LID 3). Mov Disord. 2017;32(12):1701-9. https://doi.org/10.1002/mds. 27131.

4. Goetz CG, Nutt JG, Stebbins GT. The Unified Dyskinesia Rating Scale: presentation and clinimetric profile. Mov Disord. 2008;23(16):2398-403. https://doi.org/10.1002/mds.22341.

5. Fahn S, Elton R, Members of the UPDRS Development Committee. Unified Parkinson's disease rating scale. In: Fahn S, Marsden C, Calne D, Goldstein M, editors. Recent developments in Parkinson's disease, vol 2. Florham Park: Macmillan Health Care Information; 1987. p. 153-63, 293-304. 
6. Rodriguez-Blazquez C, Alvarez M, Arakaki T, Campos Arillo V, Chana P, Fernandez W, et al. Selfassessment of disability in Parkinson's disease: the MDS-UPDRS part II versus clinician-based ratings. Mov Disord Clin Pract. 2017;4(4):529-35. https:// doi.org/10.1002/mdc3.12462.

7. Goetz CG, Tilley BC, Shaftman SR, Stebbins GT, Fahn S, Martinez-Martin P, et al. Movement Disorder Society-sponsored revision of the Unified Parkinson's Disease Rating Scale (MDS-UPDRS): scale presentation and clinimetric testing results. Mov Disord. 2008;23(15):2129-70. https://doi.org/ $10.1002 /$ mds. 22340 .

8. Hauser RA, Friedlander J, Zesiewicz TA, Adler $\mathrm{CH}$, Seeberger LC, O'Brien CF, et al. A home diary to assess functional status in patients with Parkinson's disease with motor fluctuations and dyskinesia. Clin Neuropharmacol. 2000;23(2):75-81.

9. Movement Disorder Society-Unified Parkinson's Disease Rating Scale. Milwaukee: Movement Disorder Society; 2019. https://www.movementdis orders.org/MDS-Files1/PDFs/Rating-Scales/MDSUPDRS_English_FINAL_Updated_August2019.pdf.

10. Horvath K, Aschermann Z, Kovacs M, Makkos A, Harmat M, Janszky J, et al. Minimal clinically important differences for the experiences of daily living parts of Movement Disorder Societysponsored unified Parkinson's disease rating scale. Mov Disord. 2017;32(5):789-93. https://doi.org/10. 1002/mds.26960.

11. Elmer LW, Juncos JL, Singer C, Truong DD, Criswell SR, Parashos S, et al. Author correction to: Pooled analyses of phase III studies of ADS-5102 (amantadine) extended-release capsules for dyskinesia in Parkinson's disease. CNS Drugs. 2018;32(4): 399-400. https://doi.org/10.1007/s40263-0180510-z.

12. Elmer LW, Juncos JL, Singer C, Truong DD, Criswell SR, Parashos S, et al. Pooled analyses of phase III studies of ADS-5102 (amantadine) extended-release capsules for dyskinesia in Parkinson's disease. CNS Drugs. 2018;32(4):387-98. https://doi.org/10.1007/ s40263-018-0498-4.

13. Mehta SH, Pahwa R, Tanner CM, Hauser RA, Johnson R. Effects of Gocovri (amantadine) extended release capsules on non-motor symptoms in patients with Parkinson's disease and dyskinesia. Neurology and Therapy. 2021. https://doi.org/10. 1007/s40120-021-00246-3 (Epub ahead of print. PMID: 33864229).

14. Rodriguez-Blazquez C, Rojo-Abuin JM, AlvarezSanchez M, Arakaki T, Bergareche-Yarza A, Chade A, et al. The MDS-UPDRS Part II (motor experiences of daily living) resulted useful for assessment of disability in Parkinson's disease. Parkinsonism Relat Disord. 2013;19(10):889-93. https://doi.org/10. 1016/j.parkreldis.2013.05.017.

15. Pahwa R, Isaacson S, Jimenez-Shaheed J, Malaty IA, Deik A, Johnson R, et al. Impact of dyskinesia on activities of daily living in Parkinson's disease: results from pooled phase 3 ADS-5102 clinical trials. Parkinsonism Relat Disord. 2019;60:118-25. https://doi.org/10.1016/j.parkreldis.2018.09.005.

16. Okuma Y. Practical approach to freezing of gait in Parkinson's disease. Pract Neurol. 2014;14(4): 222-30. https://doi.org/10.1136/practneurol-2013000743.

17. Cucca A, Biagioni MC, Fleisher JE, Agarwal S, Son A, Kumar P, et al. Freezing of gait in Parkinson's disease: from pathophysiology to emerging therapies. Neurodegener Dis Manag. 2016;6(5):431-46. https://doi.org/10.2217/nmt-2016-0018.

18. Heremans E, Nieuwboer A, Vercruysse S. Freezing of gait in Parkinson's disease: where are we now? Curr Neurol Neurosci Rep. 2013;13(6):350. https://doi. org/10.1007/s11910-013-0350-7.

19. Giladi N. Medical treatment of freezing of gait. Mov Disord. 2008;23(suppl 2):S482-8. https://doi.org/ $10.1002 /$ mds. 21914 .

20. Malkani R, Zadikoff C, Melen O, Videnovic A, Borushko E, Simuni T. Amantadine for freezing of gait in patients with Parkinson disease. Clin Neuropharmacol. 2012;35(6):266-8. https://doi.org/10. 1097/WNF.0b013e31826e3406.

21. Diederich NJ, Fenelon G, Stebbins G, Goetz CG. Hallucinations in Parkinson disease. Nat Rev Neurol. 2009;5(6):331-42. https://doi.org/10.1038/ nrneurol.2009.62.

22. Forsaa EB, Larsen JP, Wentzel-Larsen T, Goetz CG, Stebbins GT, Aarsland D, et al. A 12-year population-based study of psychosis in Parkinson disease. Arch Neurol. 2010;67(8):996-1001. https://doi.org/ 10.1001/archneurol.2010.166.

23. Lee AH, Weintraub D. Psychosis in Parkinson's disease without dementia: common and comorbid with other non-motor symptoms. Mov Disord. 2012;27(7):858-63. https://doi.org/10.1002/mds. 25003.

24. Hauser RA, Pahwa R, Tanner CM, Oertel W, Isaacson SH, Johnson R, et al. ADS-5102 (amantadine) extended-release capsules for levodopa-induced dyskinesia in Parkinson's disease (EASE LID 2 Study): interim results of an open-label safety study. J Parkinsons Dis. 2017;7(3):511-22. https://doi.org/ 10.3233/JPD-171134. 
25. Turcano P, Mielke MM, Bower JH, Parisi JE, Cutsforth-Gregory JK, Ahlskog JE, et al. Levodopa-induced dyskinesia in Parkinson disease: a population-based cohort study. Neurology. 2018;91(24):e2238-43. https://doi.org/10.1212/ WNL.0000000000006643.
26. Isaacson $\mathrm{SH}$, Fahn S, Pahwa R, Tanner CM, Espay AJ, Trenkwalder C, et al. Parkinson's patients with dyskinesia switched from immediate release amantadine to open-label ADS-5102. Mov Disord Clin Pract. 2018;5(2):183-90. https://doi.org/10.1002/ mdc3.12595. 